\title{
Comparative Study of Synthesis of CdO-ZnO Nanocomposite Thin Films by Different Methods: A Review
}

\author{
Jeevitesh K. Rajput and L.P. Purohit* \\ Semiconductor Research Lab, Department of Physics, Gurukula Kangri University, Haridwar, India.
}

Received: November 29, 2016; Accepted: December 21, 2016; Published: December 24, 2016

*Corresponding author: L.P. Purohit, Semiconductor Research Lab, Department of Physics, Gurukula Kangri University, Haridwar, India. Email; proflppurohitphys@gmail.com

\begin{abstract}
In the present work, different methods of CdO-ZnO thin films prepared on the glass substrate were compared viz. magnetron sputtering; spray pyrolysis and sol-gel techniques. The structural, optical and electrical properties of CdO-ZnO thin films were analyzed for the suitability of the material in context of stability and device formation. Among these methods, sol-gel method is best to synthesize $\mathrm{CdO}-\mathrm{ZnO}$ thin films due to its low cost, easy precursors, polycrystalline nature of thin films and good approximation with optical properties.
\end{abstract}

Key Words: Magnetron sputtering; Spray pyrolysis; Sol-gel; $\mathrm{CdO}-\mathrm{ZnO}$

\section{Introduction}

Recently the binary compositions of semiconductors attract researchers due to novel properties and different application like photovoltaic, photo catalytic, gas/humidity sensor etc. Binary nanocomposites such as CdO-ZnO, CdS-ZnS, ZnO-MgO, $\mathrm{ZrO}_{2}-\mathrm{Y}_{2} \mathrm{O}_{3}, \mathrm{SnO}_{2}-\mathrm{TiO}_{2}$ and $\mathrm{CdSe}-\mathrm{CdS}$ show very good stable transport properties and lead different electronic devices [16]. CdO-ZnO nanocomposites have interesting properties for different applications. Morphological and optical properties of nanostructured $\mathrm{Zn}$ and $\mathrm{Cd}$ oxides mixture films have been previously studied $[7,8]$ and have established that the optical properties and the band gap of the mixture of both can be controlled by the oxides content ratio. In recent years, hetero structures of $\mathrm{ZnO}$ with metals or semiconductors have attracted much attention because of their enhanced optical and photo catalytic properties $[9,10]$. Among the reported published articles, CdO-ZnO composites offer interesting properties, due to various defect present (e.g., vacancies $\left(\mathrm{V}_{0}\right)$ and interstitials $\left(\mathrm{O}_{\mathrm{i}}\right)$ oxygen atoms; and $\mathrm{Zn}$ vacancies $\left(\mathrm{V}_{\mathrm{Zn}}\right)$ and interstitials $\left(\mathrm{Z}_{\mathrm{ni}}\right)$ zinc atoms), which increase the photoluminescence (PL) in different regions of the optical spectrum and, also increase the potential for optoelectronic applications $[11,12]$. Zinc oxide is a
II-VI semiconductors, owing to the availability of a large variety of techniques to prepare it, the large number of structures and nanostructures in which it can be condensed, as well as the large and varied number of industrial applications [13]. ZnO has a wurtzite structure in which the oxygen atoms are arranged in a hexagonal-close-packed lattice with zinc atoms occupying half the tetrahedral sites. This is a very well known semiconductor with a wide band gap in the near ultraviolet of $\sim 3.37 \mathrm{eV}$ at room temperature [14]. Cadmium oxide (CdO) is also a well-known II-VI n-type semiconductor that has interesting properties for optoelectronic applications due to its large band gap, low electrical resistivity and high optical transmittance in the visible region of the solar spectrum [15]. It can be found in various types of nano structures with a variety of properties and applications such as UV and visible photoluminescence, photo catalysts and field emission, ambient temperature ferromagnetism and high electronic mobility [16] as well as photo detectors, solar cells, piezoelectric devices [17]. It has been well studied as a sensor material to detect most of the reducing gases [18]. CdO has a rock salt crystal structure with a direct band gap of $2.2 \mathrm{eV}$ to 2.5 $\mathrm{eV}$ and indirect band gap of $1.98 \mathrm{eV}$, which makes it useful for a wide range of applications such as solar cells, photodiodes, and transparent electrodes and sensors [19-22]. These interesting materials have been synthesized by various techniques, including electrode position, molecular beam epitaxy [23], sol-gel [24], thermal decomposition technique [25], pulsed laser deposition [26], spray pyrolysis [27], magnetron sputtering [28] and ultrasonic spray pyrolysis (USP) techniques [29]. In the present work we have done a comparative study of transports properties of $\mathrm{ZnO}$-CdO thin films synthesis by sol-gel, magnetron sputtering and spray pyrolisis techniques.

\section{Deposition of thin films}

\section{Sol-gel Method}

Sol-gel method is an attractive method to obtain the films of different materials and this is well known for its low cost, 
reproducibility and possibility of producing cheap large-area films. Different types of source compounds are continuously used by researchers like acetates, chlorides and nitrates of cadmium and zinc. Similarly respective solvent and stabilizers are also used for preparation of required solution. Spin coater was used for thin film deposition.

Ziabari and Ghodsi [30] were prepared sol-gel CdO-ZnO thin films on the glass substrate at room temperature using zinc acetate dihydrate $\left[\mathrm{Zn}\left(\mathrm{COOCH}_{3}\right)_{2} \cdot 2 \mathrm{H}_{2} \mathrm{O}\right]$ and cadmium acetate dehydrate $\left[\mathrm{Cd}\left(\mathrm{COOCH}_{3}\right)_{2} \cdot 2 \mathrm{H}_{2} \mathrm{O}\right] .0 .5$ molarity precursor solution was prepared by 2-Methoxyethanol $\left(\mathrm{C}_{3} \mathrm{H}_{8} \mathrm{O}_{2}\right)$ and monoethanolamine $\left(\mathrm{C}_{2} \mathrm{H}_{7} \mathrm{NO}, \mathrm{MEA}\right)$ as a solvent and stabilizer. The composite $\mathrm{CdO}-\mathrm{ZnO}$ thin films were volume ratio of $\mathrm{Cd}: \mathrm{Zn}$ of $0: 1,1 / 4: 3 / 4,1 / 2: 1 / 2,3 / 4: 1 / 4$, and $1: 0$ was prepared. E. Mosquera et al. [31] were dissolved nitrates in deionised water and ethanol mixture using PVA and prepared nanoparticles of CdO-ZnO. Based of published literature acetates are suitable candidate for thin film preparation.

Li et al [24]. Were used ZnAc and CdAc as source of Zn and Cd. 0.4 molarity solution was prepared using 2-methoxyethenol and MEA as solvent and stabilizer respectively? The molar ratio of MEA to zinc acetate was maintained at 1.0, and the concentration of zinc acetate was $0.4 \mathrm{M}$. Then $\mathrm{Cd}\left(\mathrm{CH}_{3} \mathrm{COO}\right)_{2} \cdot 2 \mathrm{H}_{2} \mathrm{O}$ was added into the solution with the $\mathrm{Cd} / \mathrm{Zn}$ nominal ratio of $0,5,10,20$ and 30 at.\%. The solution was stirred at room temperature for more than $4 \mathrm{~h}$ in order to get a well-mixed precursor solution. The films were deposited with a spin coater at the rotating speed of 5000 rpm for $20 \mathrm{~s}$. After each coating, the as deposited films were dried at $300{ }^{\circ} \mathrm{C}$ in air for $15 \mathrm{~min}$ to evaporate the organics.

\section{Sputtering method}

The magnetron sputtering is a widely used and versatile technique that allows us to monitor the growth by controlling relevant parameters like sputtering power and sputtering time, substrate temperature, ratio of sputtering gas, sputtering target, etc.

Kumar et al [32]. Prepared $\mathrm{Cd}$ doped $\mathrm{ZnO}$ thin films by dc magnetron sputtering at different wt. \% $(2,4,10)$ of $\mathrm{Cd}$ using respective targets of composition. The sputtering was started form base pressure $8 \times 10^{-6} \mathrm{mbar}$ and distance between target and substrate was fixed $50 \mathrm{~mm}$. Sui et al [28]. were synthesized $\mathrm{Zn}_{1-\mathrm{x}} \mathrm{Cd}_{\mathrm{x}} \mathrm{O}$ films prepared on quartz substrates using mixture of oxygen and argon as sputtering gas by the direct current (dc) reactive magnetron sputtering. Sui et al [28]. Were used zinc cadmium alloys of $99.999 \%$ purity of varied proportion as sputtering targets? The vacuum chamber was evacuated to a base pressure of $5 \times 10^{-6} \mathrm{~Pa}$, and then sputtering gases, high purity $40 \mathrm{sccm}$ Oxygen (99.99\%) and $20 \mathrm{sccm}$ Ar (99.99\%) were introduced with a constant total pressure about 5.0 Pa. The sputtering current and sputtering voltage were $150 \mathrm{~mA}$ and 400 $\mathrm{V}$, respectively. The substrate temperature was held at $773 \mathrm{~K}$ during the films deposition and the deposition time was $60 \mathrm{~min}$ for all samples.

\section{Spray pyrolysis}

This is another widely used synthesis technique which has been continuously used by researchers. Instead of spin coating spray pyrolysis can be used for thin film preparation. Spray pyrolysis is being used for the preparation of a large number of undoped and doped simple and complex semiconducting oxide films. In this process chemical and thermal both reactions took place at the time of deposition which can enhance uniformity with very high growth rates.

Tarwal et al [33]. sprayed $\mathrm{Cd}$ doped $\mathrm{ZnO}$ thin films with low doping percentage (1-5\%) on glass substrate using acetates as a source of cadmium and zinc. The distance spray nozzle to substrate was fixed $22 \mathrm{~cm}$ and solution spray rate $5 \mathrm{~cm}^{3} /$ min was maintained. Acharya et al [27]. were prepared spray solution by mixing appropriate volumes of zinc nitrate $\left[\mathrm{Zn}\left(\mathrm{NO}_{3}\right)_{2}\right]$ and cadmium acetate $\left[\mathrm{Cd}\left(\mathrm{CH}_{3} \mathrm{COO}\right)_{2} \cdot \mathrm{H}_{2} \mathrm{O}\right]$ of $0.2 \mathrm{M}$ concentration. Thin film was prepared at optimize temperature $400{ }^{\circ} \mathrm{C}$ by spray pyrolysis method. Nozzle to substrate distance was $28 \mathrm{~cm}$ whereas spray rate was $1 \mathrm{ml} / \mathrm{min}$.

\section{Transport Properties of CdO-ZnO thin films}

\section{Structural Characterization}

Several application of thin films demands good crystal quality, to conform the amorphous or crystalline nature and lattice parameters of the samples X-ray diffraction analysis (XRD) was done. Structural properties of CdO-ZnO thin films were carried out using XRD patterns where sharp peaks in spectra indicating crystal structure and hump indicating amorphous structure. The Scherrer's formula used to calculate grain size of nanostructure

Ziabari and Ghodsi [30] give structural properties by XRD patterns of CdO-ZnO thin films of sol-gel method. XRD pattern studies were carried out in order to get an idea of the structural changes produced in $\mathrm{CdO}-\mathrm{ZnO}$ films as a result of the increase of $\mathrm{Cd}$ content. It was found that the grain size increases from 20 to $34 \mathrm{~nm}$, when Cd ratio increases. The results exhibit the presence of $\mathrm{Cd}$ and $\mathrm{Zn}$ peaks with $\mathrm{Cd} / \mathrm{Zn}$ atomic percentage ratio of 0.17 , 0.44 and 1.55 for volume ratio of $\mathrm{Cd}: \mathrm{Zn}$ as $1 / 4: 3 / 4,1 / 2: 1 / 2$ and $3 / 4: 1 / 4$,respectively. G. Li et al [24]. reported stable hexagonal crystal structure for low Cd doped $\mathrm{ZnO}$ with grain size 40-50 nm. Kumar et al [32]. observed the XRD patterns of thin films of cadmium ( 0 wt.\%, 2 wt.\%, 4 wt.\% and 10 wt.\%) doped zinc oxide which has been deposited on a glass substrate by reactive DC magnetron sputtering [18]. The spectra exhibits only (002) peaks at around $2 \theta=34.50^{\circ}$ depending on the Cd content, which clearly indicates a single phase film having a structure of hexagonal wurtzite $\mathrm{ZnO}$ without any substantial formation of a separate Cd phase. The Full Width Half Maximum of the films decreased when the $\mathrm{Cd}$ concentration increased, hence indicating the enhancement in crystal quality. The grain size 41-53 nm increased with the increase of $\mathrm{Cd}$ concentration, but at higher $\mathrm{Cd}$ concentration (10 wt. \%) it decreased slightly $40.70 \mathrm{~nm}$.

Sui et al [28]. reported structural properties of CdO-ZnO nanocompopsite thin films. The samples with higher $\mathrm{Zn}$ ratio alloy thin films are of hexagonal wurtzite structures and highly 
c-axis oriented and slightly shifted for Cd ratio with small grain $18.3 \mathrm{~nm}$ to $9.7 \mathrm{~nm}$. The samples with higher Cd ratio alloy films show rock salt structure with (200) orientation.

Acharya [27] et al. examined the lattice constant and grain size of cadmium doped zinc oxide films synthesized by spray pyrolysis method. The preferential orientation of all the films has been found to be along (002) plane. The analysis revealed that all the films are of polycrystalline in nature having a hexagonal wurtzite type crystal structure and suggests that the films do not have any phase segregation. The crystalline size decreased with increase in Cd concentration. The structural parameter show a small variation like lattice constant $0.521-0.523 \mathrm{~nm}$ and grain size $180-58 \mathrm{~nm}$ as with low cadmium doping up to 5 at.\%. Tarwal et al [33]. also observed hexagonal wurtzite crystal structure for low wt. \% Cd doped $\mathrm{ZnO}$ thin films and grain size decreases from $44 \mathrm{~nm}$ to $33 \mathrm{~nm}$ and deterioration in the crystallinity with Cd wt. $\%$ in $\mathrm{ZnO}$ thin films.

Form the above discussion it's clear that all the film have similar crystal structure of nanocomposite, irrespective of the method adopted for preparation. However, its shows that grain size depends method, sol-gel spin coated thin film have least grain size and largest for sputtered thin films.

\section{Optical Properties}

Transparent metal oxides show interesting optical properties which play a crucial role in different application like solar cell window layer. Transmittance and absorbance of thin film directly related to band gap of nanocomposites which can be calculated by Tauc's plot method. Li et al [24]. Shows the optical transmission of $\mathrm{ZnO}$ :Cd films with different low wt.\% Cd doping concentrations [12]. The optical transmission of all the films is over $80 \%$ in the visible region of $400-600 \mathrm{~nm}$, which reveals that the films are highly transparent in the visible region. The optical band gap decreases from 3.27 to $3.16 \mathrm{eV}$, the optical absorption edge exhibits a red shift with the rise of $\mathrm{Cd}$ doping concentration from 0 to 30 at.\%. The narrowing band gap is due to the existence of $\mathrm{Cd}$ impurities in the $\mathrm{ZnO}$ structure, which induce the formation of new recombination centres with lower eission energy. Ziabari and Ghodsi [30] reported optical properties of CdO-ZnO nanocmposites and observed transparency of thin films in visible region decreased with $\mathrm{CdO}$ concentration in $\mathrm{CdO}-\mathrm{ZnO}$ thin films. The optical band gap of CdO-ZnO thin film decreases from $3.28 \mathrm{eV}$ to $2.23 \mathrm{eV}$ with increasing $\mathrm{CdO}$.

Sui et al [28]. studied the effect of the Cd concentration on optical band-gap of $\mathrm{Zn}_{1-\mathrm{x}} \mathrm{Cd}_{\mathrm{x}} \mathrm{O}$ alloy sputtered thin films, the optical characteristics of the alloy thin films were investigated by an UV-Vis-NIR spectrophotometer. The absorption spectra of the $\mathrm{Zn}_{1-\mathrm{x}} \mathrm{Cd}_{\mathrm{x}} \mathrm{O}$ films shows the variation of the absorbance with wavelength, the sharp band-edge absorption can be observed in all the absorption spectra and suggesting that all the $\mathrm{Zn}_{1-\mathrm{x}} \mathrm{Cd}_{\mathrm{x}} \mathrm{O}$ films have good crystal quality. The band-gap $\left(\mathrm{E}_{\mathrm{g}}\right)$ value of $\mathrm{Zn}_{1}$. ${ }_{\mathrm{x}} \mathrm{Cd}_{\mathrm{x}} \mathrm{O}$ is obtained from the optical absorption spectra by using Tauc's relation. The optical band-gap of the $\mathrm{Zn}_{1-\mathrm{x}} \mathrm{Cd}_{\mathrm{x}} \mathrm{O}$ was varying from 3.24 to $2.22 \mathrm{eV}$. Kumar et al [32]. shown a small band gap can tuned 3.37-3.14 eV with lower wt. \% doping of cadmium in $\mathrm{ZnO}$.
Acharya et al [27]. have shows the transmittances of spray pyrolysised thin films were collected by using UV-visible spectrophotometer. It was observed that, the films were highly transparent in the visible region and the transmittance was low in the ultraviolet region. All the films exhibit around $80 \%$ transmittance in the visible region and sharp ultraviolet absorption edge corresponding to undoped film suffers significant red shift with the increase of cadmium content. The band gap energies was observed $3.25 \mathrm{eV}$ to $2.94 \mathrm{eV}$ for Cd:ZnO with $\mathrm{Cd}$ concentrations. Tarwal et al [33]. show direct allowed transition and the optical band gap energies are found in the range of 3.25-3.16 eV with increasing $\mathrm{Cd}$ ratio in $\mathrm{Cd}$-doped $\mathrm{ZnO}$ thin films.

It can be noticed that all the CdO-ZnO films were highly transparent in visible for synthesis techniques. The band gap decreased as the $\mathrm{Cd}$ concentration increased with similar range for sol-gel and sputtering techniques but a small variation $[0.31$ $\mathrm{eV}$ ) was observed for spray pyrolysis.

\section{Electrical Properties}

Most of electronic devices need minimum value of resistivity, but with transparent oxide high resistivity is always a major problem. Electronic properties of thin film can be calculated using Hall Effect and dc characterization system.

Li et al [24]. analysed temperature dependent resistivity of $\mathrm{Cd}: \mathrm{ZnO}$ thin films and observed semiconducting behaviour for all the thin films. The resistivity of thin films at room temperature was decreased with $\mathrm{Cd}$ concentration up to 10 at.\%, which shows the minimum resistivity $0.0341 \Omega \mathrm{cm}$. Ziabari and Ghodsi [30] discussed the behaviour of carrier concentration (n), resistivity $(\rho)$ and carrier mobility $(\mu)$ of $\mathrm{CdO}-\mathrm{ZnO}$ thin films prepared by sol-gel method [19]. The carrier concentration increases with Cd ratio up to $\mathrm{Cd} 1 / 2: \mathrm{Zn} 1 / 2$ and after that decreases slightly with further increase in $\mathrm{Cd}$ ratio. The carrier mobility increases from 1.5 to $45 \mathrm{~cm}^{2} \mathrm{~V}^{-1} \mathrm{~s}^{-1}$ as increases $\mathrm{Cd}$ concentration.

Kumar et al [32]. discussed the resistivity of Cd (0 wt. \%, 2 wt. \%, 4 wt. \% and 10 wt. \%) doped ZnO films were prepared by sputtering method. The resistivity of the $\mathrm{Cd}$ doped $\mathrm{ZnO}$ decreased with an increase of $\mathrm{Cd}$ concentration, i.e. 0 wt. \%, 2 wt. \%, 4 wt. \%. The Hall mobility and carrier concentration are simultaneously increased due to the increase of Cd concentration. Sui et al [28]. performed hall experiment at room temperature for electrical characterization of $\mathrm{Zn}_{1-\mathrm{x}} \mathrm{Cd}_{\mathrm{x}} \mathrm{O}$ thin films and observed n-type semiconductors. The resistivity of the film decrease dramatically from $2.27 \times 10^{2}$ to $1.94 \times 10^{-3} \Omega \mathrm{cm}$ with increasing the $\mathrm{Cd}$ content from $\mathrm{x}=0$ to 1 . The Hall mobility of the films decreases exponentially from 95.18 to $5.74 \mathrm{~cm}^{2} / \mathrm{V}$-s with the Cd content $\mathrm{x}$ increasing from $\mathrm{x}=0$ to 0.5 .

Acharya et al [27]. analysis the resistivity measurements in $\mathrm{ZnO}$ and $\mathrm{Cd}: \mathrm{ZnO}$ films prepared by spray pyrolysis technique and using a dc-two probe method for the temperature range from $150 \mathrm{~K}$ to $400 \mathrm{~K}$ have been carried out. All the curves demonstrate the semiconductor type of behaviour. The resistance per unit length decreased with the increase in temperature from 150 


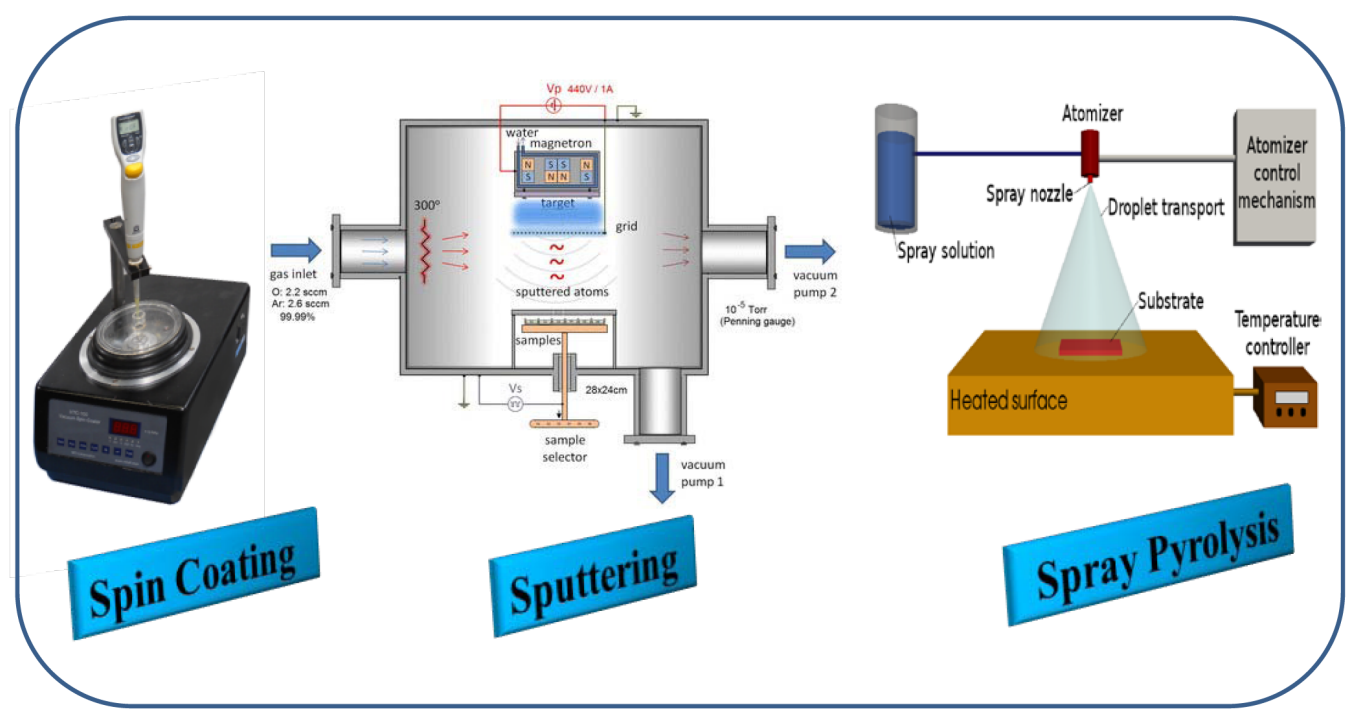

Figure 1: Flow chart for this film preparation using different techniques.

Table: Different parameters of $\mathrm{ZnO-CdO} \mathrm{thin} \mathrm{films} \mathrm{prepared} \mathrm{by} \mathrm{sol-gel,}$ sputtering and spray pyrolysis techniques.

\begin{tabular}{|c|c|c|c|c|c|}
\hline Method & $\begin{array}{c}\text { Grain } \\
\text { size(nm) }\end{array}$ & $\begin{array}{c}\text { Max. } \\
\text { Intensity } \\
\text { peak }\end{array}$ & Structure & $\begin{array}{c}\text { Diffraction } \\
\text { peak (20) }\end{array}$ & $\begin{array}{c}\text { Band gap } \\
\text { (eV) }\end{array}$ \\
\hline Sol-gel & 20 & $(002)$ & Wurtzite & $34^{0}$ & $3.27-3.16$ \\
\hline Sputtering & 41 & $(002)$ & Wurtzite & $34.50^{0}$ & $3.24-2.22$ \\
\hline $\begin{array}{c}\text { Spray } \\
\text { Pyrolysis }\end{array}$ & 180 & $(002)$ & Wurtzite & $34^{0}$ & $3.20-2.94$ \\
\hline
\end{tabular}

K up to nearly (325 K) for all prepared films. This should help in designing a particular Cd:ZnO film for its use in solar energy storage devices. In region 200-325 K, the decrease in the resistivity could be due to the thermal excitation of electrons into the conduction band. In region 326-349 K, the sharp increase in resistivity is attributed to vigorous oxygen adsorption on the film surface. In region 350-375 K, the resistivity is not much affected by the temperature change.

\section{Conclusion}

The structural, electrical and optical properties of the sol-gel, sputtering and spray pyrolysis derived $\mathrm{CdO}-\mathrm{ZnO}$ nanostructured thin films prepared at different Cd content have been compared. The grain size and surface roughness of the films were increased with Cd content in sol-gel and sputtering technique but decreases in spray pyrolysis. Crystal Structure was same wurzite in all three cases. The optical analysis of the films indicates that the optical band gap depends on the Cd composition. The band gap is decreases as increases $\mathrm{Cd}$ content in $\mathrm{ZnO}$ films is all the cases but most of difference in sputtering method about $1.02 \mathrm{eV}$. Electrical measurements showed the semiconducting nature of $\mathrm{Cd}$ doped $\mathrm{ZnO}$ thin films. The resistance per unit length decreased with the increase in temperature of film prepared by spray pyrolysis. Due to these theoretical analyses of comparative investigation we have concluded that among these methods sol-gel method is best to synthesize CdO-ZnO due to its easy precursors, allowing growth of thin film with large area at low temperature, controllable thickness, desired deposition rate and good optical properties.

\section{References}

1. Assumpt C. Nwanya, P.R. Deshmukh, Rose U. Osujib, Malik Maazad, C.D. Lokhande, Fabian I. Ezema. Synthesis, characterization and gassensing properties of SILAR deposited ZnO-CdO nano-composite thin film. Sensors and Actuators B 206 (2015) 671-678. DOI: 10.1016/j. snb.2014.09.111.

2. Nicholas S. McCool, John R. Swierk, Coleen Teresa Nemes, Charles A. Schmuttenmaer, Thomas E Mallouk. Dynamics of Electron Injection in $\mathrm{SnO}_{2} / \mathrm{TiO}_{2}$ Core/Shell Electrodes for Water-Splitting Dye-Sensitized Photoelectrochemical Cells, Journal of Physical Chemistry Letters. 2016;7 (15):2930-2934. DOI: 10.1021/acs.jpclett.6b01528

3. Wen-Jian Kuang, Qing Li, YiSun, JingChen, HarmTolner, Near-bandedge emission characteristics of $\mathrm{ZnO}-\mathrm{MgO}$ core-shell quantum-dots. Materials Letters. 2016;178:27-30.

4. Le Wang, Hongwei Wei, Yingju Fan, Xinzheng Liu, Jinhua Zhan. Synthesis, Optical Properties, and Photocatalytic Activity of OneDimensional CdS@ZnS Core-Shell Nanocomposites. Nanoscale Res Lett. 2009;4(6):558-564. doi: 10.1007/s11671-009-9280-3.

5. Samiksha Sikarwar, B.C. Yadav, Satyendra Singh, G.I. Dzhardimalieva, S.I. Pomogailo, Nina D. Golubeva, et al. Fabrication of nanostructured yttria stabilized zirconia multilayered films and their optical humidity sensing capabilities based on transmission. Sensors and Actuators. 2016;232:283-291.

6. Wen Xiong. Electronic structure and intersubband magnetoabsorption spectra of $\mathrm{CdSe} / \mathrm{CdS}$ core-shell nanowires. Superlattices and Microstructures. 2016;98:158-173.

7. A. Yousef, N.A.M. Barakat, T. Amna, A.R. Unnithan, S.S. Al-Deyab, $\mathrm{H}$. Yong Kim. Influence of CdO-doping on the photoluminescence properties of $\mathrm{ZnO}$ nanofibers: Effective visible light photocatalyst for waste water treatment. J. Lumin. 2012;132(7): 1668-1677. 
8. G. Singh, A.K. Srivastava, K. Senthil, J.S. Tawale, M. Deepa, K.Yong. Structural, Optical and Electrical Properties of Nano-Structured $\mathrm{Cd}: \mathrm{ZnO}$ Thin Films Prepared via Sol-Gel Derived Spin Coating Method. J. Nanoeng. Nanomanuf. 2011;1(1):77-83.

9. K. Senthil, Y. Tak, M. Seol, K. Yong. Synthesis and Characterization of ZnO Nanowire-CdO Composite Nanostructures. Nanoscale Res. Lett. 2009;4(11):1329-1334. doi: 10.1007/s11671-009-9401-z.

10.H. Karami. Investigation of sol-gel Synthesized CdO-ZnO Nanocomposite for CO Gas Sensing. Int. J. Electrochem. Sci. 2010;5:720-730.

11. H. Karami, A. Aminifar, H. Tavallali, Z. A. Namdar. PVA-Based Sol-Gel Synthesis and Characterization of $\mathrm{CdO}-\mathrm{ZnO}$ Nanocomposite. J. Cluster Sci. 2010;21(1):1-9. DOI: 10.1007/s10876-009-0277-y.

12. R. Saravanan, H. Shankar, T. Prakash, V. Narayanan, A. Stephen. ZnO/ $\mathrm{CdO}$ composite nanorods for photocatalytic degradation of methylene blue under visible light. Mater. Chem. Phys. 2011;125:277-280.

13. Ravinder Kaur, A. V. Singh, R. M. Mehra. Structural, electrical and optical properties of sol-gel derived yttrium doped $\mathrm{ZnO}$ films. phys. stat. sol. 2005;202(6):1053-1059. DOI: 10.1002/pssa.200420006.

14.F. Wang, D. Zhao, Z. Guo, L. Liu, Z. Zhang, D. Shen. Artificial leaf structures as a UV detector formed by the self-assembly of $\mathrm{ZnO}$ nanoparticles. Nanoscale. 2013; 5(7):2864-2869. doi: 10.1039/ c3nr33748k.

15. Trilok Kumar Pathak, Vinod Kumar, H.C. Swart, L.P. Purohit. P-type conductivity in doped and codoped $\mathrm{ZnO}$ thin films synthesized by $\mathrm{RF}$ magnetron sputtering, Journal of Modern Optics. 2015;62(17):13681373.

16. Vinod Kumar, Vijay Kumar, S. Soma, L.P. Purohit, O.M. Ntwaeaborwa, H.C. Swart. Role of swift heavy ions irradiation on the emission of boron doped $\mathrm{ZnO}$ thin films for near white light application. Journal of Alloys and Compounds. 2014;594:32-38.

17. N. Kumar, R. Kaur, R. M. Mehra. Characterization of sol-gel derived yttrium-doped n-ZnO/p-Si heterostructure. Materials Science-Poland. 2006;24:375-383.

18. XiaoyanCai, Dan Hu, Shaojuan Deng, Bingqian Han, Yan Wang, Jinming $\mathrm{Wu}$, et al. Isopropanol sensing properties of coral-like $\mathrm{ZnO}-\mathrm{CdO}$ composites by flash preparation via self-sustained decomposition of metal-organic complexes. Sensors and Actuators B. 2014;198:402410.

19. A.S. Lanje, R.S.Ningthoujam, S.J.Sharma, R.B.Pode. Luminescence and electrical resistivity properties of cadmium oxide nanoparticles. Indian J. Pure Appl. Phys. 2011;49:234-238.

20. M. Kul, A.S. Aybek, E. Turan, M. Zor, S. Irmak. Effects of fluorine doping on the structural properties of the CdO films deposited by ultrasonic spray pyrolysis. Sol. Energy Mater. Sol. Cells. 2007;91(20):1927-1933.
21. K. Gurumurugan, D. Mangalaraj, S.K. Narayandass, K. Sekar, C.P.G. Vallabhan. Characterization of transparent conducting CdO films deposited by spray pyrolysis, Semicond. Sci. Technol. 1994;9:18271832.

22. R. Maity, K.K. Chattopadhyay. Synthesis and characterization of aluminum-doped CdO thin films by sol-gel process. Sol. Energy Mater. Sol. Cells. 2006;90:597-606.

23.L. Li, Z. Yang, Z. Zuo, J.H. Lim, J.L. Liu. Thermal stability of CdZnO hin films grown by molecular-beam epitaxy. Appl. Surf. Sci. 2010;256(14):4734-4737.

24. Gang Li, Xuebin Zhua, Xianwu Tanga, Wenhai Songa, ZhaorongYanga, JianmingDaia, et al. Doping and annealing effects on ZnO:Cd thin films by sol-gel method. Journal of Alloys and Compounds. 2011;509:48164823.

25.W.E. Mahmoud, A.A. Al-Ghamdi. Synthesis of $\mathrm{CdZnO}$ thin film as a potential candidate for optical switches. Opt. Laser Technol. 2010;42(7):1134-1138.

26. R. Vinod Kumar, K.J. Lethy, P.R. Arunkumar, R.R. Krishnan, N. Venugopalan Pillai,V.P. Mahadevan Pillai, et al. Effect of cadmium oxide incorporation on the microstructural and optical properties of pulsed laser deposited nanostructured zinc oxide thin films. Mater. Chem. Phys. 2010;121(3):406-413.

27. A.D. Acharya, Shweta Moghe, Richa Panda, S.B. Shrivastava, Mohan Gangrade, T. Shripathi, et al. Effect of Cd dopant on electrical and optical properties of $\mathrm{ZnO}$ thin films prepared by spray pyrolysis route,Thin Solid Films. 2012;525(15):49-55.

28. Yingrui Sui, YonggaoYue, Yanping Song, Yan Cao, Bin Yao, Jihui Lang, et al. Effects of Cd concentration on microstructure and optical properties of the ternary $\mathrm{Zn}_{1-\mathrm{x}} \mathrm{Cd}_{\mathrm{x}} \mathrm{O}$ alloy thin films synthesized by magnetron sputtering, Materials Research Bulletin. 2015;70:348353.

29. N. Kavasoglu, A.S. Kavasoglu, S. Oktik. Observation of negative photoconductivity in $(\mathrm{ZnO})_{\mathrm{x}}(\mathrm{CdO})_{1-\mathrm{x}}$ films. J. Phys. Chem. Solids. 2009;70(3-4):521-526.

30. A. Abdolahzadeh Ziabari, F.E. Ghodsi. Optoelectronic studies of sol-gel derived nanostructured $\mathrm{CdO}-\mathrm{ZnO}$ composite films. Journal of Alloys and Compounds. 2011;509(35):8748- 8755.

31. Edgar Mosquera, Ignaciodel Pozo, Mauricio Morel. Structure and red shift of optical band gap in $\mathrm{CdO}-\mathrm{ZnO}$ nanocomposite synthesized by the sol gel method. Journal of Solid State Chemistry. 2013;206:265271.

32. A. Guru Sampath Kumar, L. Obulapathi, T. Sofi Sarmash, D. Jhansi Rani, M. Maddaiah, T. SubbaRao, et al. Structural, Electrical and Optical Properties of Cd Doped $\mathrm{ZnO}$ Thin Films by Reactive dc Magnetron Sputtering. J. O. M. 2015;67:834-839.

33. N.L. Tarwal, A.R. Patil, N.S. Harale, A.V. Rajgure, S.S. Suryavanshi, W.R. Bae, et al. Gas sensing performance of the spray deposited Cd-ZnO thin films. Journal of Alloys and Compounds. 2014;598:282-288. 